\title{
Mass loss of the Antarctic ice sheet until the year 3000 under a sustained late-21st-century climate
}

\section{Article \\ Cite this article: Chambers C, Greve R, Obase T, Saito F, Abe-Ouchi A (2022). Mass loss of the Antarctic ice sheet until the year 3000 under a sustained late-21st-century climate. Journal of Glaciology 68(269), 605-617. https://doi.org/ $10.1017 /$ jog.2021.124}

Received: 20 June 2021

Revised: 2 November 2021

Accepted: 3 November 2021

First published online: 22 December 2021

\section{Keywords:}

Antarctic glaciology; ice and climate; ice-sheet modelling

\section{Author for correspondence:}

Christopher Chambers,

E-mail: youstormorg@gmail.com (c) The Author(s), 2021. Published by Cambridge University Press. This is an Open Access article, distributed under the terms of the Creative Commons Attribution licence (https://creativecommons.org/licenses/by/4.0/), which permits unrestricted re-use, distribution, and reproduction in any medium, provided the original work is properly cited.

\author{
Christopher Chambers ${ }^{1}$ (D), Ralf Greve ${ }^{1,2}$ (D), Takashi Obase ${ }^{3}$, Fuyuki Saito ${ }^{4}$ \\ and Ayako Abe-Ouchi ${ }^{3}$
}

\begin{abstract}
${ }^{1}$ Institute of Low Temperature Science, Hokkaido University, Sapporo, Japan; ${ }^{2}$ Arctic Research Center, Hokkaido University, Sapporo, Japan; ${ }^{3}$ Atmosphere and Ocean Research Institute, The University of Tokyo, Kashiwa, Japan and ${ }^{4}$ Japan Agency for Marine-Earth Science and Technology, Yokohama, Japan
\end{abstract}

\section{Abstract}

Ice-sheet simulations of Antarctica extending to the year 3000 are analysed to investigate the long-term impacts of 21st-century warming. Climate projections are used as forcing until 2100 and afterwards no climate trend is applied. Fourteen experiments are for the 'unabated warming' pathway, and three are for the 'reduced emissions' pathway. For the unabated warming path simulations, West Antarctica suffers a much more severe ice loss than East Antarctica. In these cases, the mass loss amounts to an ensemble average of $\sim 3.5 \mathrm{~m}$ sea-level equivalent (SLE) by the year 3000 and $\sim 5.3 \mathrm{~m}$ for the most sensitive experiment. Four phases of mass loss occur during the collapse of the West Antarctic ice sheet. For the reduced emissions pathway, the mean mass loss is $\sim 0.24 \mathrm{~m}$ SLE. By demonstrating that the consequences of the 21 st century unabated warming path forcing are large and long term, the results present a different perspective to ISMIP6 (Ice Sheet Model Intercomparison Project for CMIP6). Extended ABUMIP (Antarctic BUttressing Model Intercomparison Project) simulations, assuming sudden and sustained iceshelf collapse, with and without bedrock rebound, corroborate a negative feedback for ice loss found in previous studies, where bedrock rebound acts to slow the rate of ice loss.

\section{Introduction}

The Antarctic ice sheet (AIS) contains more than half of the Earth's fresh water, enough to raise sea levels by $58 \mathrm{~m}$ (Fretwell and others, 2013). An ice mass of $7.4 \mathrm{~mm}$ sea-level equivalent (SLE) was lost from the AIS between 1992 and 2017 (The IMBIE team, 2018), and there is evidence to suggest that parts of the West Antarctic Ice Sheet (WAIS) may already have begun an irreversible retreat (Joughin and others, 2014; Rignot and others, 2014).

The possibility of WAIS retreat and collapse was first presented by Mercer (1968) and there is palaeoclimatic evidence that it collapsed during past warm periods (Pollard and DeConto, 2009; Alley and other, 2015; Dutton and others, 2015; Gasson and others, 2016; Turney and others, 2020). In contrast to the East Antarctic Ice Sheet (EAIS), the WAIS is grounded on a bed that is mostly well below the sea level (Fig. 1) making it primarily a marine ice sheet. The WAIS bedrock bathymetry also deepens inwards in many areas, making it susceptible to marine-ice-sheet instability (e.g. Schoof, 2007). The WAIS is bounded by the two largest iceshelf systems in the world, the Ross and the Ronne-Filchner, which currently act to buttress the grounded ice sheet (e.g. Joughin and Alley, 2011) and reduce ice flow across long, below-sea-level grounding lines.

To estimate the future sea-level-rise contribution from the Antarctic and Greenland ice sheets through the end of the 21st century, the Coupled Model Intercomparison Project Phase 6 (CMIP6) (Eyring and others, 2016) includes the Ice Sheet Model Intercomparison Project for CMIP6 (ISMIP6; Nowicki and others, 2016, 2020). ISMIP6 uses output from Earth system models run under future emissions scenarios, as atmospheric and oceanic forcing for ice-sheet models including the SImulation COde for POLythermal Ice Sheets (SICOPOLIS; Greve and SICOPOLIS Developer Team, 2021) used here. The set-up and results of the Antarctica ISMIP6 projections are described in Seroussi and others (2020), and the results specifically obtained with SICOPOLIS are discussed in detail in Greve and others (2020). Using simulations from 13 international groups, ISMIP6 found an Antarctic mass loss that varied between -7.8 and $30.0 \mathrm{~cm}$ SLE from 2015 to 2100 under the 'unabated warming path' of Representative Concentration Pathway (RCP) 8.5 (Seroussi and others, 2020). The WAIS mass loss varied greatly among the simulations with the greatest loss simulated being 18.0 $\mathrm{cm}$ SLE, while the EAIS mass change varied between -6.1 and $8.3 \mathrm{~cm}$. The results for the RCP2.6 pathway (that represents substantial emissions reductions) lie within the uncertainty interval of the results for RCP8.5. Payne and others (2021) compared the impact of CMIP5 and CMIP6 forcings and found that the projected sea-level contribution at 2100 under the CMIP6 scenarios falls within the CMIP5 range for the AIS. Edwards and others (2021) explored the uncertainty of the projections in greater detail by using statistical emulation of the ice-sheet models, which allowed the consideration of a much larger range of climate scenarios and forcings. This study essentially confirmed the ISMIP6 findings: by 2100, the AIS 

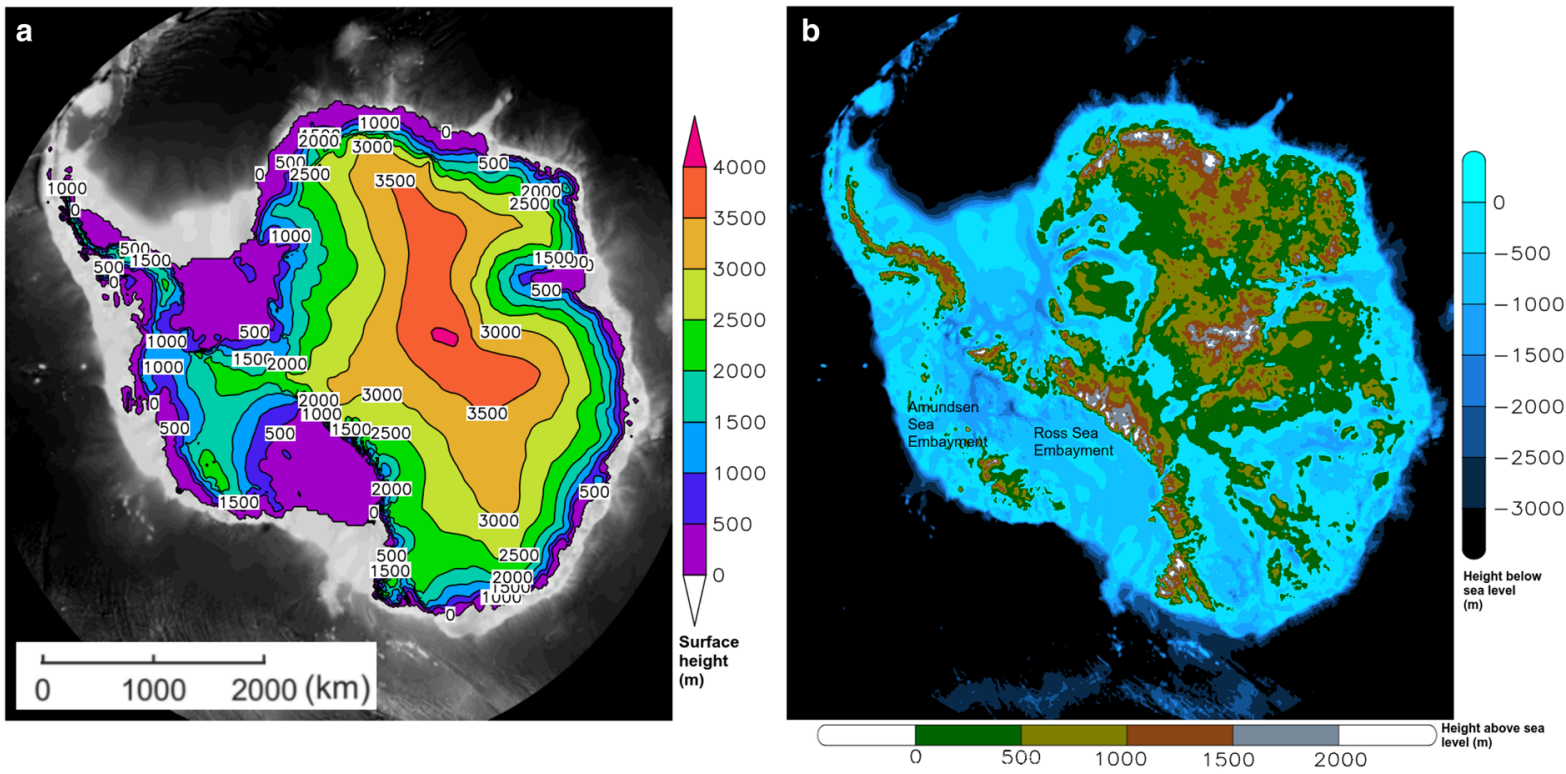

Fig. 1. SICOPOLIS year 2015 (a) simulated surface topography and (b) bedrock elevation above and below sea level. The bedrock elevation is from Bedmap2 (Fretwell and others, 2013) mapped onto the $8 \mathrm{~km}$ grid.

showed a response encompassing the range from a significant mass loss to a slight mass gain due to the competing processes of increasing ice loss at and near the margins, and increased snowfall accumulation.

Although the ISMIP6 projections extend to the year 2100, other studies have investigated longer term AIS change. To do this some have used statistical relationships between past temperatures and global sea levels (Schaeffer and others, 2012; Levermann and others, 2013). Alternatively, Golledge and others (2015) used ice-sheet models to demonstrate that atmospheric warming in excess of $1.5-2^{\circ} \mathrm{C}$ above present, triggers ice-shelf collapse and a centennial to millennial-scale response by the AIS. They simulated a contribution to sea-level-rise from Antarctica under higher emission scenarios of $0.6-3 \mathrm{~m}$ by the year 2300 . Similarly, Garbe and others (2020) found that at $>2^{\circ} \mathrm{C}$ of global average warming, the WAIS is committed to long-term partial collapse. They also found distinct regimes in the rates of sea-level rise per degree, with a doubling in the rate if warming becomes $>2{ }^{\circ} \mathrm{C}$. Lipscomb and others (2021) used ISMIP6 forced sensitivity simulations extended to year 2500 under a constant climate to evaluate the Antarctic response to ocean forcing. They found long-term retreat of the WAIS and showed that the Amundsen sector exhibits threshold behaviour with modest retreat or complete collapse depending on parameter settings in the melt scheme, ocean forcing and basal friction law. Complete collapse of the WAIS occurred under some combinations of low basal friction and high thermal forcing anomalies. The Antarctic BUttressing Model Intercomparison Project (ABUMIP; Sun and others, 2020) compared ice-sheet model responses to a removal of iceshelf buttressing by investigating the response to sudden and sustained loss of ice shelves and found that the WAIS contributed $1.91-5.08 \mathrm{~m}$ sea-level rise due to marine ice-sheet instability over the 500 year-long simulations. These studies point to threshold behaviour in the WAIS in response to atmosphere and ocean warming.

The goal of our study is to investigate the extended effects of the climate projections used in ISMIP6. To do this, we simulate the evolution of the AIS until the year 3000 . Until 2100, we follow the ISMIP6 protocol, whereas afterwards we assume a steady, late-21st-century climate without any further trend. In this longer-term perspective, a very different picture emerges
Table 1. Physical parameters used in the simulations of this study

\begin{tabular}{|c|c|}
\hline Quantity & Value \\
\hline Density of ice, $\rho$ & $910 \mathrm{~kg} \mathrm{~m}^{-3}$ \\
\hline Density of sea water, $\rho_{\mathrm{sw}}$ & $1028 \mathrm{~kg} \mathrm{~m}^{-3}$ \\
\hline Gravitational acceleration, $g$ & $9.81 \mathrm{~m} \mathrm{~s}^{-2}$ \\
\hline Length of year, $1 \mathrm{a}$ & $31556926 \mathrm{~s}$ \\
\hline Power-law exponent, $n$ & 3 \\
\hline Residual stress, $\sigma_{0}$ & $10 \mathrm{kPa}$ \\
\hline Flow enhancement factor, $E$ & grounded ice: 5 , floating ice: 1 \\
\hline Melting temperature at low pressure, $T_{0}$ & $273.16 \mathrm{~K}$ \\
\hline Clausius-Clapeyron gradient, $\beta$ & $8.7 \times 10^{-4} \mathrm{~K} \mathrm{~m}^{-1}$ \\
\hline Universal gas constant, $R$ & $8.314 \mathrm{~J} \mathrm{~mol}^{-1} \mathrm{~K}^{-1}$ \\
\hline Heat conductivity of ice, $\kappa$ & $9.828 \mathrm{e}^{-0.0057 T[K]} \mathrm{W} \mathrm{m}^{-1} \mathrm{~K}^{-1}$ \\
\hline Specific heat of ice, $c$ & $(146.3+7.253 T[\mathrm{~K}]) \mathrm{J} \mathrm{kg}^{-1} \mathrm{~K}^{-1}$ \\
\hline Latent heat of ice, $L$ & $3.35 \times 10^{5} \mathrm{~J} \mathrm{~kg}^{-1}$ \\
\hline Sliding coefficient, $C_{\mathrm{b}}^{0 a}$ & $\begin{array}{l}\text { Range from } 0.1 \text { to } \\
2.7621 \mathrm{~m} \mathrm{a}^{-1} \mathrm{~Pa}^{-1}\end{array}$ \\
\hline Sliding exponents, $(p, q)^{a}$ & $(3,2)$ \\
\hline Sub-melt-sliding parameter, $\gamma^{a}$ & $1^{\circ} \mathrm{C}$ \\
\hline $\begin{array}{l}\text { Coefficient for water-layer-enhanced basal } \\
\text { sliding, } c^{a}\end{array}$ & 9 \\
\hline Threshold water-layer thickness, $H_{\mathrm{w}}^{0}{ }^{a}$ & $5 \mathrm{~mm}$ \\
\hline $\begin{array}{l}\text { Density } \times \text { specific heat of the lithosphere, } \\
\rho_{\mid} C_{l}\end{array}$ & $2000 \mathrm{~kJ} \mathrm{~m}^{-3} \mathrm{~K}^{-1}$ \\
\hline Heat conductivity of the lithosphere, $\kappa_{l}$ & $3 \mathrm{~W} \mathrm{~m}^{-1} \mathrm{~K}^{-1}$ \\
\hline $\begin{array}{l}\text { Thickness of the thermal upper boundary } \\
\text { layer of the lithosphere, } H_{l}\end{array}$ & $2 \mathrm{~km}$ \\
\hline Flexural stiffness of the lithosphere, $K_{l}$ & $10^{25} \mathrm{~N} \mathrm{~m}$ \\
\hline Asthenosphere density, $\rho_{a}$ & $3300 \mathrm{~kg} \mathrm{~m}^{-3}$ \\
\hline Time lag for the relaxing asthenosphere, $\tau_{\mathrm{a}}$ & $3000 \mathrm{a}$ \\
\hline
\end{tabular}

${ }^{a}$ For details of the Weertman-Budd-type sliding law with sub-melt sliding and hydrology, see Greve and others (2020, their Eqs. (7), (8) and accompanying text).

compared to the 21st-century ISMIP6 findings. The remainder of this paper is divided into four sections. Firstly, the methods are outlined in Section 2, followed by an analysis of the simulations in Section 3. Thirdly, the results are evaluated in Section 4 , and finally a summary is provided in Section 5.

\section{Methods}

SICOPOLIS, a polythermal ice-sheet model originally created by Greve $(1995,1997)$, is used to extend the ISMIP6 experiments to the year 3000. Here, we use version 5-dev, revision 


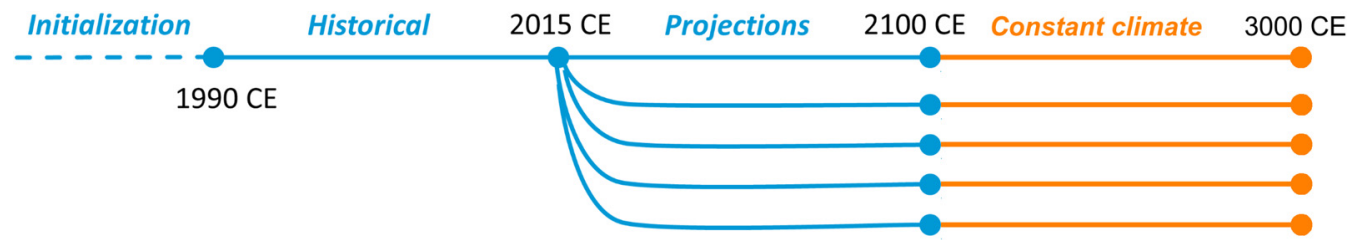

Fig. 2. Experimental design. Initialisation is followed by a historical simulation from 1990 until 2015. ISMIP6 projections run from 2015 until the end of 2100 . From 2100 to 3000 no additional forcing is applied. (Credit: edit of Fig. 1 in Greve and others (2020), originally by Martin Rückamp, AWI Bremerhaven, Germany.)

develop_63_rv5.1-62-g3c25a05 (Greve and SICOPOLIS Developer Team, 2021). The simulation set-up for ISMIP6 is described in Greve and others (2020) and only summarised here. The model domain covers the entirety of Antarctica on an $8 \mathrm{~km}$ horizontal resolution regular (structured) grid based on a polar stereographic projection, with 81 terrain-following ice layers and 41 lithosphere layers. Hybrid shallow-ice-shelfy-stream dynamics, in the modified form of Bernales and others (2017), is used for grounded ice, and the shallow-shelf approximation is used for floating ice. We employ a Weertman-Budd-type sliding law that accounts for sub-melt sliding and the subglacial waterlayer thickness (Greve and others, 2020, their Eqns (7), (8) and accompanying text). This sliding law includes the effective (ice minus water) basal pressure, assumed to be equal to the weight of the ice column above buoyancy. Therefore, the basal drag is continuous across the grounding line (approaches zero from the grounded side, equal to zero everywhere under floating ice). Gladstone and others (2017) performed numerical experiments with the Elmer/Ice model in full-Stokes mode for a simplified rectangular domain of a marine ice sheet, testing horizontal resolutions of $1.8,3.6$ and $7.2 \mathrm{~km}$. They demonstrated that, with a Weertman-Budd-type sliding law similar to ours, $7.2 \mathrm{~km}$ resolution (similar to our $8 \mathrm{~km}$ ) is sufficient to produce good results for the grounding line migration in both advance and retreat scenarios. By contrast, for a Weertman-type law that disregards the effective pressure and features a discontinuity of the basal drag across the grounding line, even $1.8 \mathrm{~km}$ does not lead to an acceptable convergence of the grounding line migration. We therefore consider our $8 \mathrm{~km}$ resolution, in combination with the Weertman-Budd-type sliding law, as sufficient for modelling marine ice-sheet dynamics, including grounding line migration, with reasonable accuracy.

The main physical parameters are listed in Table 1. A palaeoclimatic spin-up simulation is run over a full glacial cycle (140 ka) to the year 1990 as described in Greve and others (2020, Section 3.2). The basal sliding coefficient is chosen differently for the 18 IMBIE (Ice sheet Mass Balance Inter-comparison Exercise) 2016 basins (Rignot and Mouginot, 2016) to optimise the agreement between simulated and observed 1990 surface velocities (Greve and others, 2020, Section 3.2.3). Simulated vs observed ice thicknesses and surface velocities are shown in their Figures 5 and 6.

To obtain the initial state of the ice sheet shown in Figure 1a, there are then 25 years remaining to get to the year 2015, which marks the start date of the ISMIP6 projections. Therefore, an additional simulation referred to as 'Historical' in Figure 2 is run that applies NorESM1-M RCP8.5 surface mass balance, surface temperature anomalies and oceanic forcing (discussed in more detail below), to the 1960-1989 climatology (Greve and others, 2020, Section 4.1).

The ISMIP6 projections run from 2015 to 2100 with annually averaged atmospheric forcing consisting of anomalies of surface mass balance and temperature from a 1995 to 2014 climatology (Barthel and others, 2020; Nowicki and others, 2020; Seroussi and others, 2020; Payne and others, 2021). After 2100, the annual atmospheric forcing for the 10-year interval 2091-2100 is
Table 2. ISMIP6 future climate experiments discussed in this study

\begin{tabular}{lll}
\hline Scenario & GCM & Ocean forcing \\
\hline CMIP5 simulations & NorESM1-M & \\
RCP8.5 & MIROC-ESM-CHEM & Medium \\
RCP8.5 & NorESM1-M & Medium \\
RCP2.6 & CCSM4 & Medium \\
RCP8.5 & NorESM1-M & Medium \\
RCP8.5 & NorESM1-M & High \\
RCP8.5 & CCSM4 (ice-shelf collapse) & Low \\
RCP8.5 & NorESM1-M & Medium \\
RCP8.5 & HadGEM2-ES & PIGL-Medium \\
RCP8.5 & CSIRO-Mk3.6.0 & Medium \\
RCP8.5 & IPSL-CM5A-MR & Medium \\
RCP8.5 & IPSL-CM5A-MR & Medium \\
RCP2.6 & & Medium \\
CMIP6 simulations & CNRM-CM6-1 & \\
SSP5-8.5 & CNRM-CM6-1 & Medium \\
SSP1-2.6 & UKESM1-0-LL & Medium \\
SSP5-8.5 & CESM2 & Medium \\
SSP5-8.5 & CNRM-ESM2-1 & Medium \\
SSP5-8.5 & & Medium \\
Control simulation & 1995-2014 climatology & \\
None (ctrl_proj) & & Medium \\
\hline See 0 ( & &
\end{tabular}

See Nowicki and others (2020) for references for the GCMs and Greve and others (2020) for further detail on the SICOPOLIS application of the experiments.

randomly sampled such that no further warming trend is applied (similar to Calov and others, 2018) but some year to year variability remains. With the surface mass balance and temperature fixed on this 10 -year period, they remain unchanged even if the topography of ice changes over the remaining 900 years. Ice-shelf basal melt rates are calculated using the non-local quadratic melt-rate parameterisation of the 'ISMIP6 standard approach', driven by extrapolating the oceanic thermal forcing into the ice-shelf cavities (Jourdain and others, 2020). Beyond 2100, it is kept fixed at 2100 values.

All simulations are listed in Table 2. Fourteen experiments are for the 21st-century 'unabated warming path' RCP8.5 (CMIP5)/ SSP5-8.5 (Shared Socioeconomic Pathways, CMIP6), and three are for the RCP2.6/SSP1-2.6 pathway that represents substantial emission reductions and a maintenance of the global mean temperature below a $2^{\circ} \mathrm{C}$ increase. In addition, a control simulation ('ctrl_proj') uses constant climate conditions based on a 19952014 climatology and the present day oceanic forcing.

Using the NorESM1-M RCP8.5 forcing, 'High' and 'Low' sub-ice-shelf melt-rate calibrations are tested, as well as a calibration ('PIGL-medium') that applies observed basal-melt rates near the grounding line of the Pine Island Ice Shelf under all ice shelves (Jourdain and others, 2020). One experiment, 'CCSM4/RCP8.5 ice-shelf collapse', attempts to parameterise the complex processes of surface melting and hydrofracture by implementing a timedependent ice-shelf-collapse mask. It assumes that collapse occurs following a 10-year period with annual surface melt above 725 $\mathrm{mm}$ (Trusel and others, 2015).

In addition to the extended ISMIP6 simulations, the Antarctic BUttressing Model Intercomparison Project (ABUMIP; Sun and 


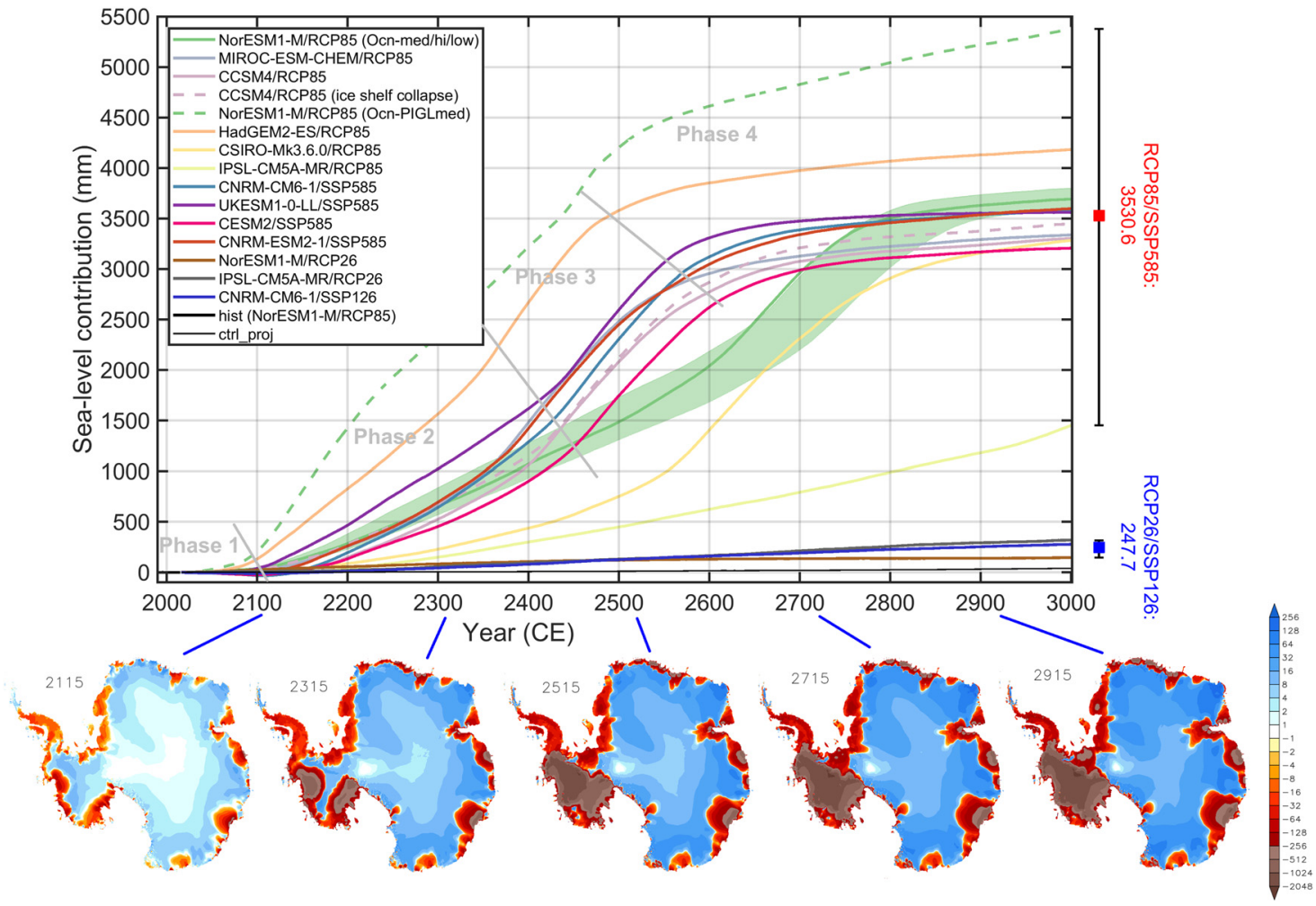

Fig. 3. Simulated ice mass change, counted positively for loss and expressed as SLE contribution. Phases mentioned in the text are labelled and diagonal grey lines are rough guides to denote the phase transitions. The red and blue boxes to the right show the means for RCP8.5/SSP5-8.5 and RCP2.6/SSP1-2.6, respectively; the whiskers show the full ranges. Map-view plots below are ice surface elevation differences from $2015(\mathrm{~m})$ for the year indicated for case MIROC-ESM-CHEM RCP8.5.

a)
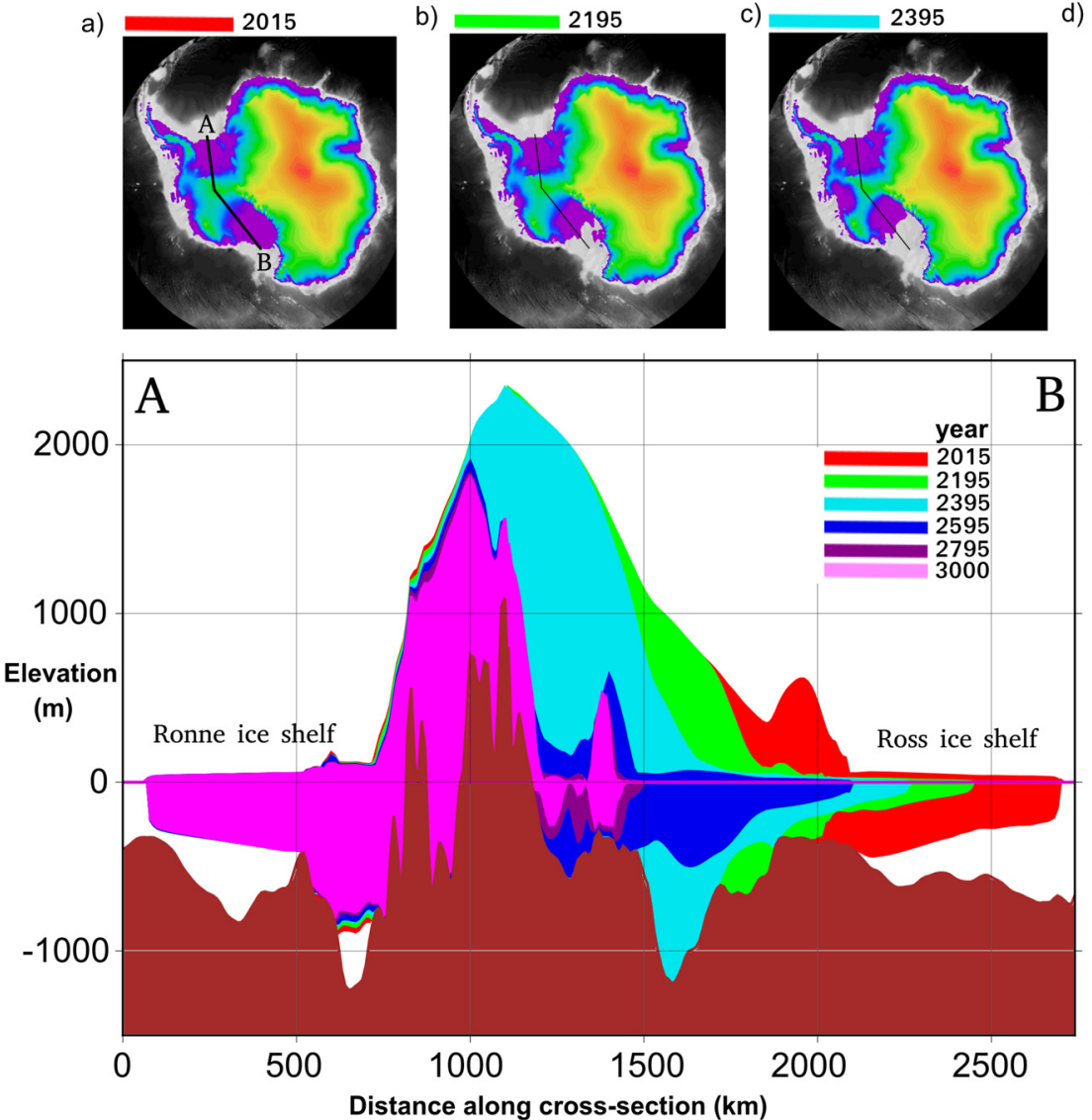

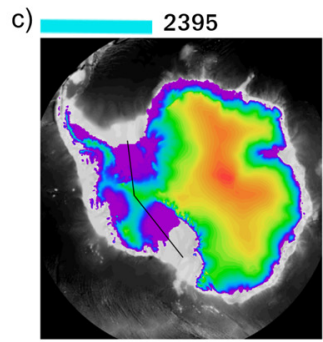

B
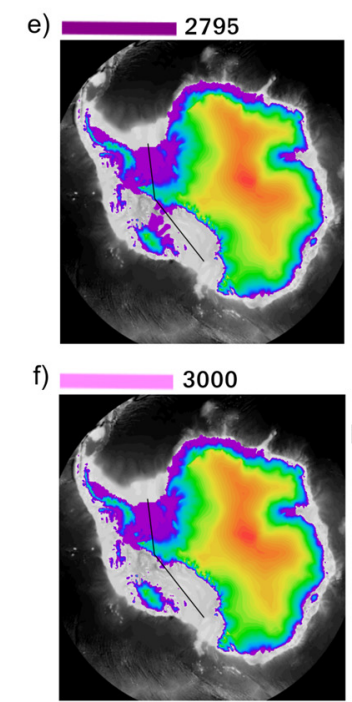

4000

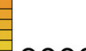

3000

2000

1000

$0 \mathrm{~m}$

Elevation

(m)

Fig. 4. West Antarctica vertical cross section for simulation MIROC-ESM-CHEM RCP8.5 showing the colour-coded ice extent for the years labelled in the side plots (a to $f$ ) that show the ice surface elevation for the year indicated. 
others, 2020) simulations are also extended to the year 3000. ABUMIP compares ice-sheet model responses to a removal of iceshelf buttressing by investigating the scenario of sudden and sustained loss of all ice shelves. This experiment was designed to show the full (if unrealistic) potential of marine-ice-sheet instability. The experiments are initialised from the same simulated 1990 state of Antarctica discussed above. The original ABUMIP simulations were run for 500 years and here we extend them an additional 500 years. The simulations are run with and without bedrock rebound (glacial isostatic adjustment). For ABUMIP, there are five experimental set-ups as summarised below (for further detail see Sun and others, 2020):

(1) Control run (abuc): 1990 (initial) forcing is applied for the duration of the simulation.

(2) Ice-shelf removal or 'float-kill' (abuk) with no bedrock rebound: all floating ice is removed at the simulation start and then continuously throughout the simulation. The bed topography remains fixed at 1990 levels.

(3) Ice-shelf removal or 'float-kill' with bedrock rebound (abukiso): the same experiment as in (2) but including glacial isostatic adjustment (GIA) using an elastic-lithosphererelaxing-asthenosphere model (parameters by Sato and Greve, 2012).

(4) Extreme sub-shelf melt and no bedrock rebound (abum): applies an extremely high melt rate of $400 \mathrm{~m} \mathrm{a}^{-1}$ underneath floating ice for a period of 500 years. This experiment acts as an alternative to the more extreme abuk and also inevitably leads to a rapid loss of all ice shelves.

(5) Extreme sub-shelf melt with bedrock rebound (abumiso): as experiment (4) but including GIA as in (3).

\section{Results}

\subsection{Extended ISMIP6 experiments}

For the ISMIP6 extended experiments, the SLE contribution due to ice-mass melt is shown in Figure 3. The graph is divided into four phases to roughly designate periods where the rates of SLE change tend to be relatively constant. Over the ISMIP6 original experiment range, which ends at 2100 (within phase 1), there is a small, and uncertain, contribution to SLE. Throughout the 21st century, the experiments are identical to those for ISMIP6; see Greve and others (2020, Section 4.2) for a detailed discussion. Beyond 2100, under a no-longer warming climate, the highemission scenarios transition to a period of relatively constant SLE change (phase 2). The onset of phase 2 varies between the cases from the latter half of the 21st century to the early 22nd century. A third phase then begins as the rate of SLE contribution increases. This phase is the period of most rapid ice-sheet mass loss and there is a fair degree of variability between the simulations in both the timing of the transition from phase 2 to 3 (between years 2340 and 2560), and in the level of SLE contribution at which this phase begins. A fourth and final phase then begins as the SLE contribution levels out, which on average produces an end SLE contribution for the high-emissions cases of $\sim 3.5 \mathrm{~m}$ by the year 3000 . Most of the cases are clustered close to this value with all but two within $\pm 0.4 \mathrm{~m}$ of the final average SLE. This is similar to a $\sim 3.3 \mathrm{~m}$ value found in Bamber and others (2009) who calculated the potential SLE contribution due to WAIS collapse by identifying gridcells below sea level on retrograde bed slopes to infer the limit of grounding line retreat.

To investigate the causes of these apparent ice-sheet mass-loss regime shifts between the four phases, here we analyse a representative case in more detail. The MIROC-ESM-CHEM RCP8.5 case lies within the cluster of cases close to the mean of the unabated
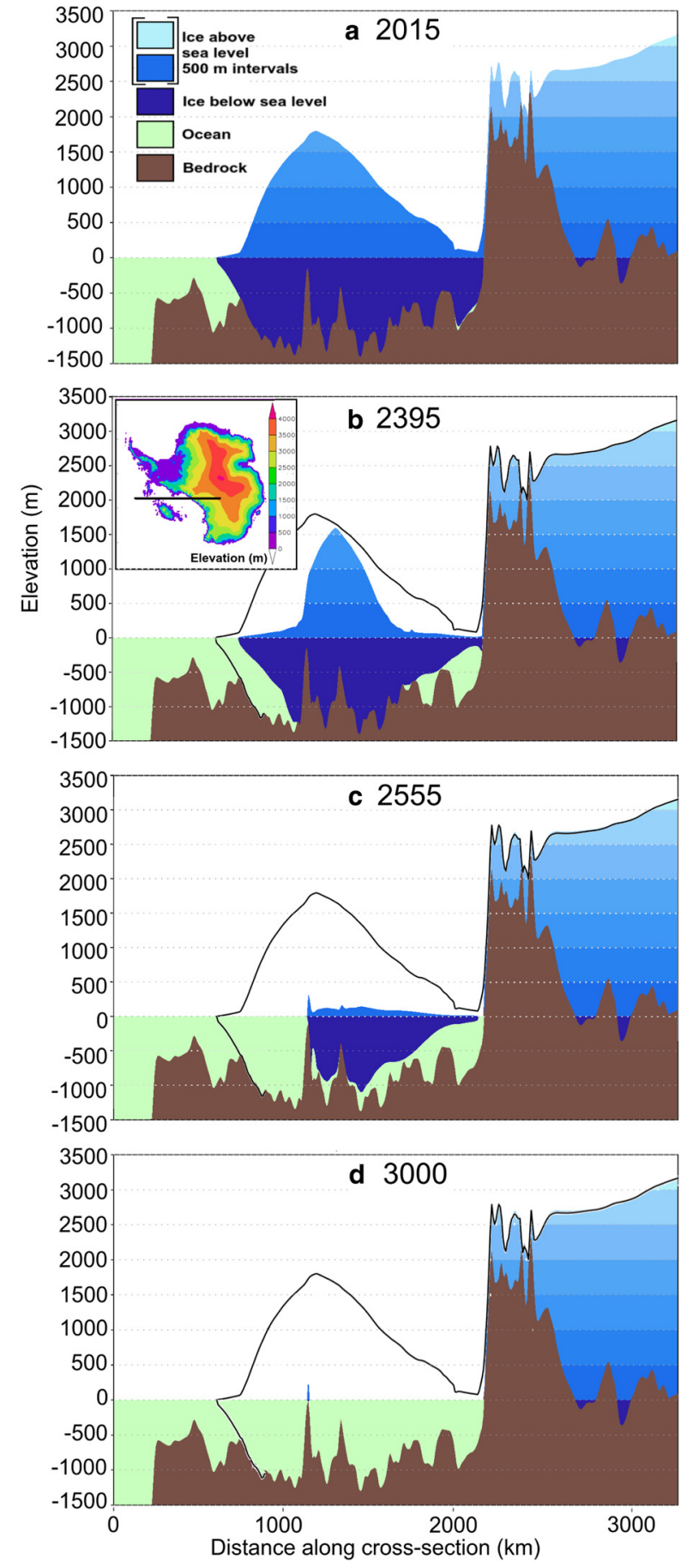

Fig. 5. Ice cross sections for simulation MIROC-ESM-CHEM RCP8.5 for (a) 2015, (b) 2395 , (c) 2555 and (d) 3000 across the black line shown on inset panel of (b). In (b, $c$ and d) the black line indicates the 2015 ice profile.

21st-century warming (RCP8.5/SSP5-8.5) runs (Fig. 3). For this case, the phase onsets occur for phase 2 around $\sim 2100$, phase 3 around $\sim 2350$ and phase 4 at $\sim 2500$. The physical controls on the similar phases in other experiments are the same.

Figure 4 shows that simulated ice-mass loss is dominated by WAIS change and it is here where the causes of the phase changes can be found. The transition from phase 1 to phase 2 is associated with the period when the Ross Ice Shelf has retreated to such a point that the Ross Sea Embayment begins a more rapid ice loss due to a reduction in the buttressing from the ice shelf (Fig. 4b). The transition to phase 3 occurs as, in addition to continued Ross Sea Embayment mass loss, the Amundsen Sea Embayment begins a rapid retreat along its inward sloping 

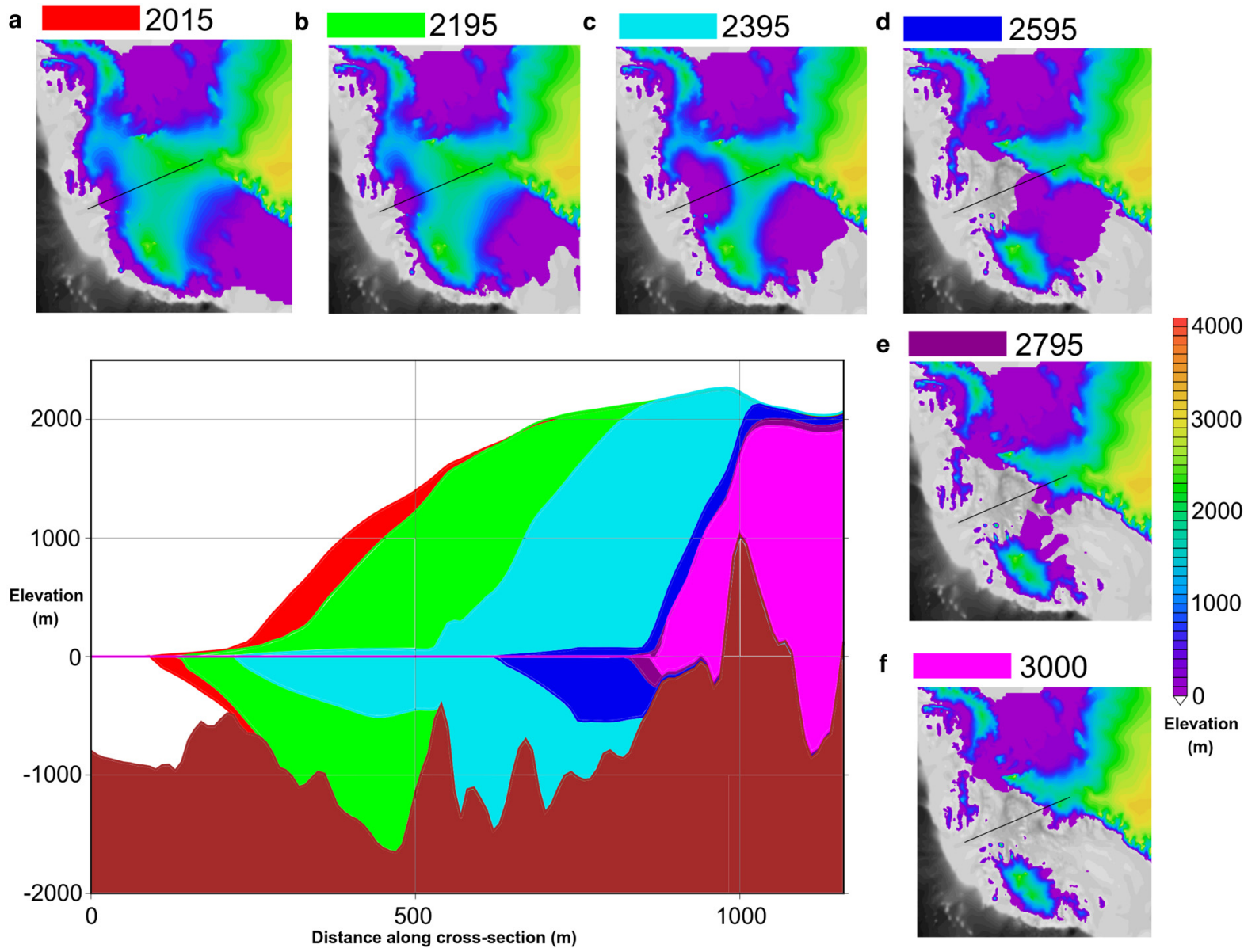

Fig. 6. Amundsen Embayment cross section for simulation MIROC-ESM-CHEM RCP8.5 showing the ice extent for the years labelled in the side plots (a-f) which show the ice surface elevation for the year indicated.

grounding lines (Fig. 4c). Phase 4 is then associated with a levelling-off in the SLE contribution as the WAIS is reduced to such an extent that the loss of the remaining ice grounded below the sea level begins to contribute less and less to the SLE contribution (Figs $4 \mathrm{~d}-\mathrm{f}$ ).

In Figure 4 cross sections through the ice along two connected diagonals through the WAIS are shown for the six times in the side panels a-f. This cross section presents a roughly flowline-oriented view from the Ronne-Filchner Ice Shelf on the left, where minimal melt occurs, to the Ross Ice Shelf on the right where collapse occurs.

The greatest change to the topography in the cross section occurs between the year 2395 and 2595 cross sections during which time a large ice shelf develops above a retrograde slope in the bed topography. The outer edge of this ice shelf lies inwards of the original Ross Ice Shelf area which is now devoid of ice. It is also during this period when the peak elevation of the cross section drops by $\sim 400 \mathrm{~m}$ with very little change either before or after. This time period coincides with when the retreat from the Amundsen Embayment and the Ross Sea Embayment meet over the Bentley subglacial trench.

An alternative cross section across the WAIS that includes part of the EAIS is shown in Figure 5 (cross section location on inset in panel b) for 4 years that are chosen to highlight the key phases of retreat. At the initialisation time (2015, Fig. 5a) the WAIS is grounded on bedrock with just a sliver of ocean in the middle where the cross section crosses the deep interior of the Ross Ice Shelf. During phase 1, the ice-sheet profile changes little, then during phase 2, ocean melting undercuts the WAIS from the Ross Ice Shelf into the Ross Sea Embayment. The surface elevation drops rapidly where this undercutting occurs, as shown for 2395 in Figure 5b. As the Amundsen Sea Embayment also loses ice, the central WAIS ridge becomes narrower.

During phase 3 , the central ridge then collapses as ice mass is evacuated due to the compounding losses from the Amundsen and Ross Sea embayments. Phase 3 transitions to phase 4 not when all the WAIS ice has melted but rather when the ice mass has been reduced to such an amount that further melt contributes little to the sea level as indicated in Figure $5 \mathrm{c}$. Beyond that the remainder of WAIS ice, now mostly detached from the bedrock can melt while contributing little to the sea level in phase 4. Therefore, the rate of mass loss levels off quickly after most of the remaining ice in the WAIS is at or very nearly at flotation. The EAIS exhibits very little change in the cross section and the slight thickening is evident on very close inspection.

A cross section through the Amundsen Embayment from the Pine Island Glacier and Thwaites Glacier area up to the WAIS ridge is shown in Figure 6. The greatest loss of ice is seen between the year 2195 and 2595 sections, however the greatest ice edge retreat is between years 2395 and 2795 because of the formation of ice shelves, the most prominent of which is seen in the year 2395 cross section. The initial ice shelf, the year 2395 ice shelf and another at year 2595 all appear to be related to shallow areas in the bedrock that act to pin the shelf and restrain the ice behind. The precarious nature of the present day ice extent is evident in the drop in bedrock from the ice edge to $\sim 490 \mathrm{~km}$ along the section.

The bedrock in the cross section is plotted for year 2015. By the latter stages in the simulation the bedrock has lifted slightly, 
Low 21st century emissions cases

a

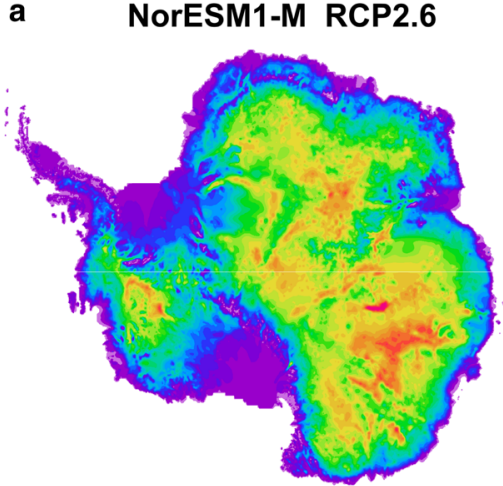

c IPSL-CM5A-MR RCP2.6

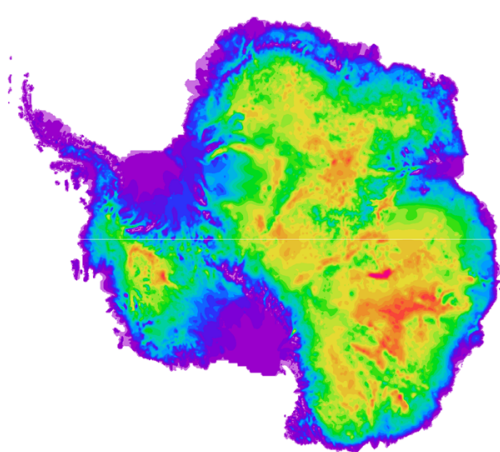

e CNRM-CM6 SSP126

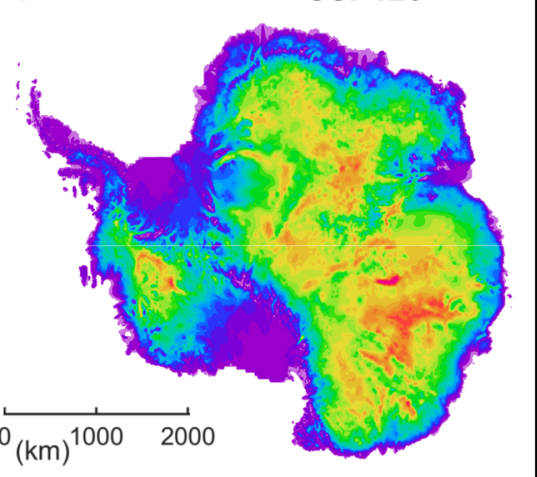

High 21st century emissions cases

b

NorESM1-M RCP8.5

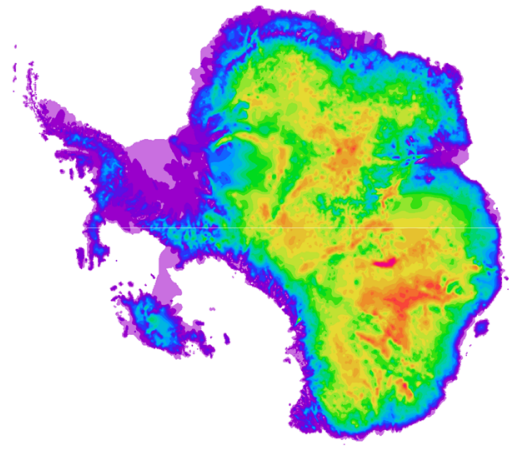

d IPSL-CM5A-MR RCP8.5

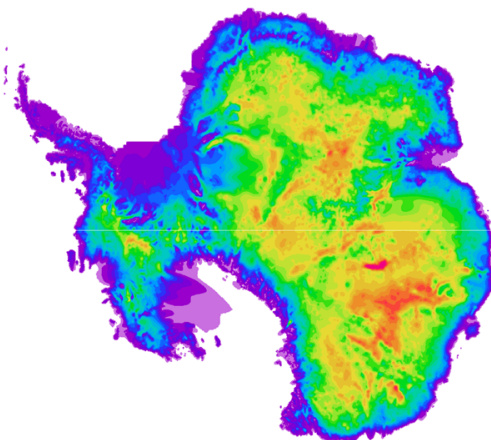

f CNRM-CM6 SSP585

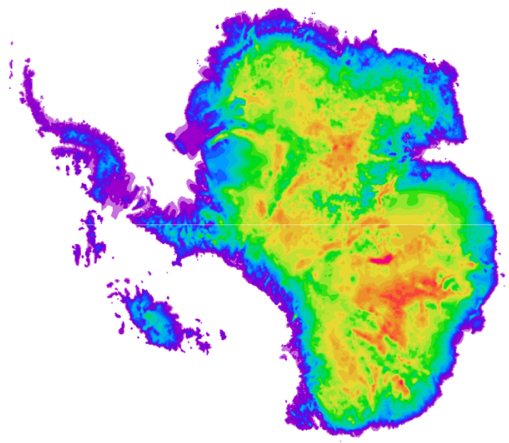

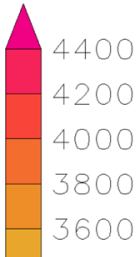

400

200

3000

2800

2600

2400

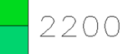

2000

1800

1600

1400

1200

m

Fig. 7. Ice thickness at year 3000 for emissions reduction cases (left) and their counterpart high-emission cases (right).

and the apparent narrow undercut in the ice seen in years 2795 and 3000 between 800 and $900 \mathrm{~km}$ along the cross section, is a consequence of this uplift rather than representing sea water undercutting the ice.

A comparison between the three low-emission simulations with their high-emission counterparts is made in Figure 7. For all of the low-emission cases there is very little noticeable change in the topography of the ice sheet as a whole, consistent with the only small contribution to sea-level from these cases (Fig. 3). For the highemission cases, all show large losses in the WAIS with the greatest losses seen in the only CMIP6 case of the three, the CNRM-CM6 SSP5-8.5, which is also the only case that loses the Ronne-Filchner Ice Shelf. This is because the ocean in this sector is relatively warmer in the ISMIP6 forcing from the CMIP6 projections. The two CMIP5 RCP85 cases, the NORESM1-M and IPSL-CM5A-MR, are quite different from each other with the NORESM1-M suffering much greater WAIS loss.

In Figure 8, the sea-level contributions by year 3000 are shown for each of three regions. Averaged across all the high-emission cases, the WAIS contributes $3.2 \mathrm{~m}$ SLE compared with just 0.26 $\mathrm{m}$ from the EAIS and $0.0044 \mathrm{~m}$ from the Antarctic Peninsula. This contrasts with the low-emission cases which have average SLE contributions from the WAIS and EAIS of 0.086 and 0.12 $\mathrm{m}$ respectively, with the Antarctic Peninsula contribution being very slightly negative at $-0.0020 \mathrm{~m}$ SLE.

In addition to the standard ISMIP6 simulation set-up, which includes a 'medium' ice-shelf basal melt calibration, two additional simulations under the NorESM1-M/RCP8.5 atmospheric forcing are run with 'high' and 'low' ice-shelf basal melt calibrations. The results are shown by the green line ('medium') and green-shaded region ('high' is the top edge of the shading and 'low' the bottom) in Figure 3. A Decrease of the ice-shelf basal melt causes a delay in the onset of the phase transitions when comparing 'high' and 'low', which produces a maximum sea-level contribution difference between 'high' and 'low', during early phase 4 , of $\sim 70 \mathrm{~cm}$. The 'medium' (standard) case behaves slightly differently, lining up closely with the 'high' case during early phase 4 . Despite these differences all calibrations gradually 
Fig. 8. SLE contribution from three regions (shown in top right) by year 3000 relative to ctrl_proj averaged across all the high (RCP8.5/SSP5-8.5, top) and low (RCP2.6/SSP1-2.6, bottom) emission cases. The whiskers show the full range of sea-level contributions across the simulations that make up the average.

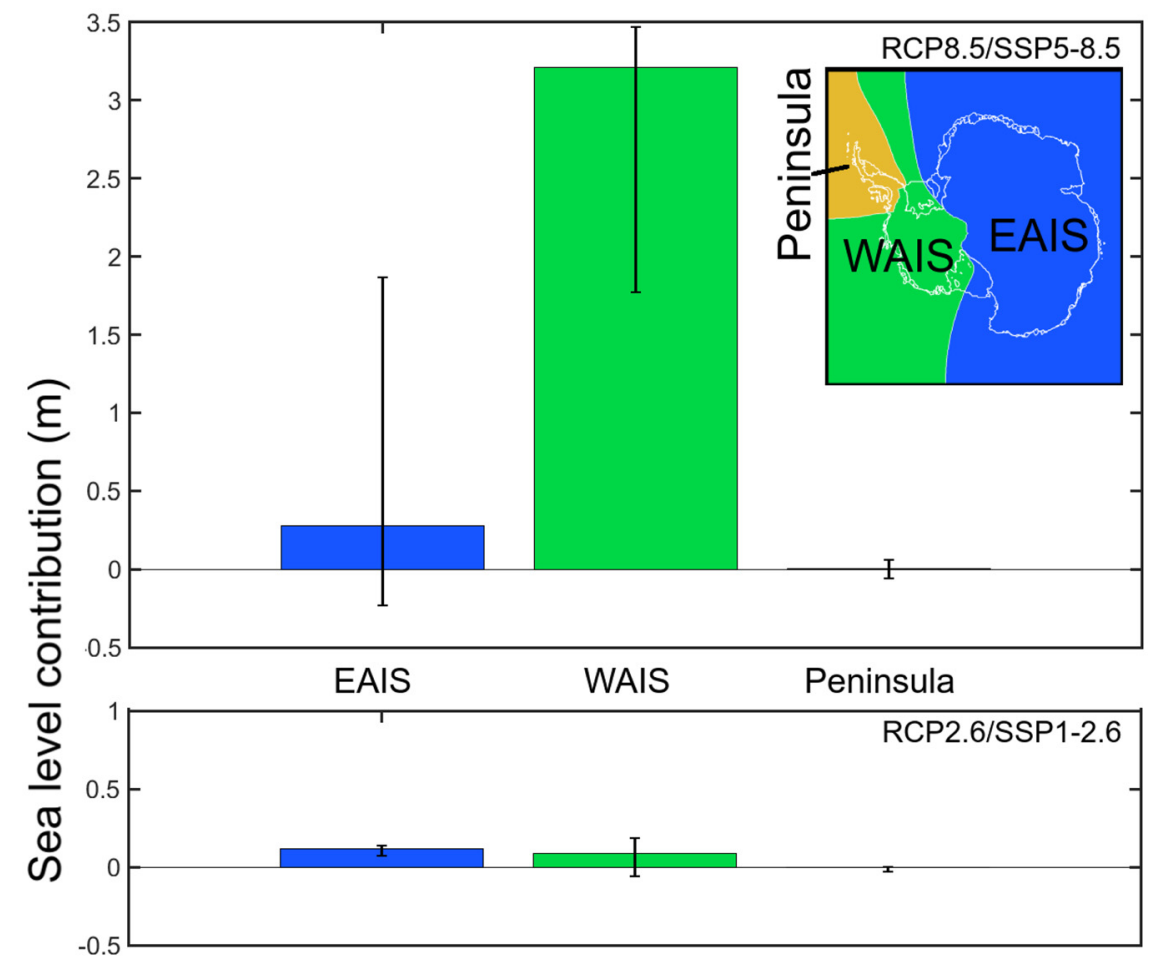

converge during phase 4 such that the sea-level contributions end up only $\sim 20 \mathrm{~cm}$ different by year 3000 .

A more extreme test is NorESM1-M RCP8.5 with the 'PIGL-medium' calibration. In this case, phase 2 onset begins earlier than the other cases and lies well within the 21st century during the original ISMIP6 simulation period. As noted in Greve and others (2020), 'It has a pronounced effect on the mass loss of the ice sheet: by 2100 , it is $216.7 \mathrm{~mm}$ SLE compared to the initial 1990 state'. In this case, the transition between phase 2 and 3 is unclear or absent and, while there is some slowing to the increase in sea-level contribution marking phase 4, sea-level contribution continues to increase at a relatively constant rate such that by the year 3000 its total contribution is $5.4 \mathrm{~m}$, the greatest of any of the cases. The reason for this greater and continuing loss is in part because this case produces EAIS losses in the Amery and Wilkes basins that are ongoing by the simulation end.

\subsection{Extended ABUMIP experiments}

For the extended ABUMIP simulations, ice thicknesses at the end of the simulations are shown in Figure 9. The ice-shelf removal (abuk, abukiso) and extremely high ice-shelf melt (abum, abumiso) both result in great changes to the ice sheet. In contrast to the extended ISMIP6 simulations, there are considerable losses in the EAIS in some of the regions where the ice is grounded below sea level. All extended ABUMIP simulations produce retreat inwards from the Amery Ice Shelf, however only in abum and abumiso is there a substantial retreat in the Wilkes Basin. These regions of greatest retreat are consistent with the original ABUMIP experiments in Sun and others (2020, Figs 2 and 3 ) while being somewhat expanded given the longer simulation period.

Both the float kill, and extreme ice-shelf melt cases were run with (abumiso, abukiso), and without, bedrock rebound (abum, abuk). Bedrock rebound occurs during, and after, ice-sheet mass loss, with the greatest amount reaching $\sim 200 \mathrm{~m}$ of lift in central West Antarctica shown in Figure 10. The Aurora Basin, in particular, shows a large difference in ice-sheet loss with and without rebound (Fig. 9a, b), yet it experiences less rebound than other areas of major ice loss.

In fact, the greatest differences in ice-sheet geometry develop over the EAIS, and this seems to be due to the slower response of the ice sheet compared to the WAIS allowing a greater cumulative impact from rebound to develop. In Figure 10, the velocity difference due to rebound indicates large regions where bedrock rebound has slowed surface velocities in the Aurora Basin and also the Amery, Slessor, Recovery and Foundation basins. The potential mechanisms responsible for these differences are considered in the discussion below.

The cases without rebound gradually lose a greater area of ice over the course of the simulations and end up with $\sim 1.5 \times$ $10^{5} \mathrm{~km}^{2}$ less ice-sheet area (Fig. 11a). Overall the cases with rebound lose $\sim 1.5 \mathrm{~m}$ less SLE (Fig. 11b).

\section{Discussion}

The extended ISMIP6 experiments show the simulated long-term effect of applying a climate based on the last 10 years of the 21 st century from the unabated warming and reduced emission climate change scenarios. The simulations apply the assumption of no climate warming or cooling beyond year 2100. Although using the same climate forcing data from ISMIP6, the long-term picture is different from the 21st-century ISMIP6 experiments showing that it is only in the long term that the consequence of different 21st-century emission scenarios becomes strikingly apparent. Under the unabated warming scenario, the AIS undergoes ice mass loss primarily in the WAIS with the rate of loss divided into the four phases as detailed in the results above. SICOPOLIS is rather insensitive to the applied climate forcing in the Amundsen Embayment due to the applied surface mass balance correction which has additional accumulation to prevent the Thwaites/Pine Island glaciers from becoming unstable before the end of the spin-up simulations. This issue is related to the model SICOPOLIS and not a general deficiency in the ISMIP6 forcing. It is possible that this reduces the rate of ice-sheet collapse in the Amundsen Embayment as compared to in the Ross Sea Embayment. Regardless, SICOPOLIS appears to be simulating a 

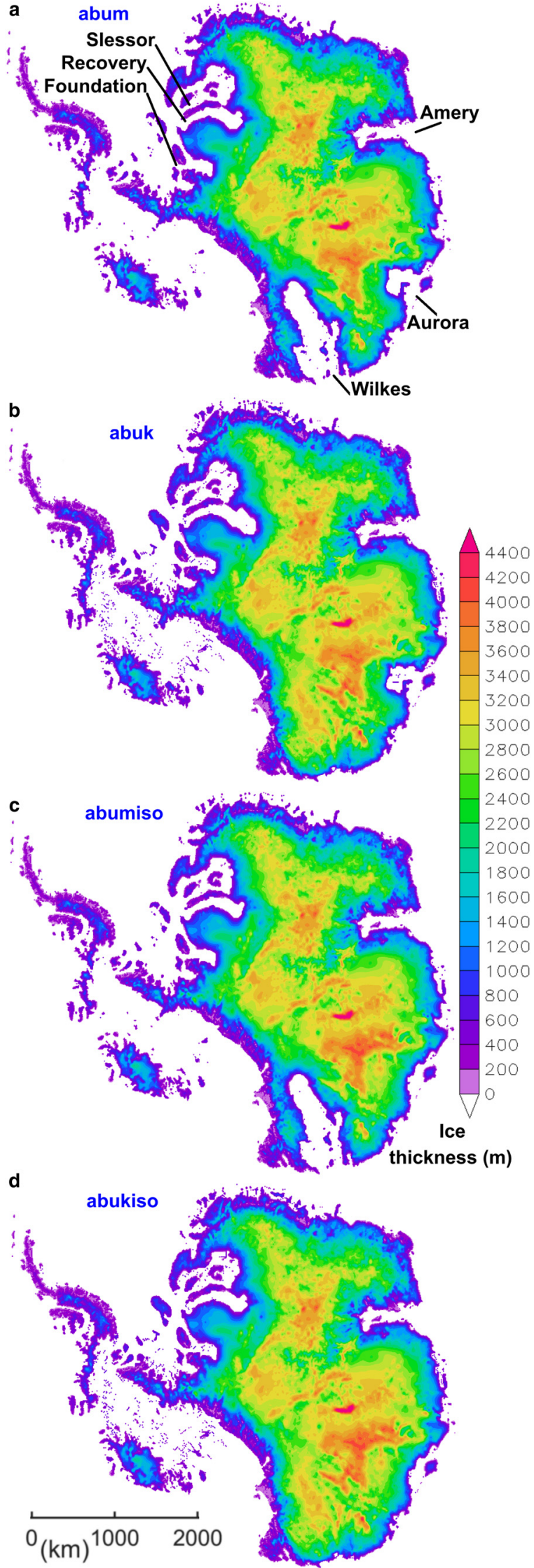

Fig. 9. ABUMIP ice thickness for year 3000 for (a) abum, (b) abuk, (c) abumiso and (d) abukiso.

marine-ice-sheet instability in these regions where the bed has a reverse slope and an initial retreat increases discharge while reducing the balance flux, leading to grounding line thinning and further retreat (e.g. Schoof, 2007). In the reduced emission scenarios the WAIS collapse does not occur indicating that a climate threshold for large WAIS loss exists and that the 2091-2100 forcing in the reduced emission cases is below this threshold. To clarify, this result is specific to the SICOPOLIS results presented here and could be substantially different from other setups that may trigger marine-ice-sheet instability in the WAIS even under constant present day conditions. The most important negative feedback opposing these positive feedbacks is due to increased precipitation in warming temperatures which has been both observed (e.g. Frieler and others, 2015) and projected for the future, over the Antarctic continent (Krinner and others, 2007; Uotila and others, 2007; Ligtenberg and others, 2013). Other negative feedbacks on ice loss include self-gravitation and isostasy.

Beyond 2100, randomly chosen surface atmospheric forcings from 2091 to 2100 are used which means that climate does not trend in time. RCP8.5 Projections beyond 2100 include significant continued warming (Bulthuis and others, 2019) that we do not consider here and is an avenue for future research. There are no forcing modifications made due to the evolution of the surface topography which means that as the WAIS ice-sheet surface lowers, there is no increase in surface melt from an increase in temperature expected due to the atmospheric lapse rate. As such the so-called 'surface-melt-elevation feedback' (e.g. Levermann and Winkelmann, 2016) is absent from these simulations. This effect should be most significant where surface temperatures rise above freezing in confined areas around the edges of the ice sheet that progress inwards as the WAIS collapses in the high-emissions scenarios.

Potentially countering this absent positive feedback for ice loss, is the increase in freezing precipitation that should penetrate inwards as the WAIS melts. This is due to the reduction in blocking topography, the penetration of open ocean inwards increasing surface fluxes that feed precipitating clouds, the temperature increase allowing the air to hold more water and the thickening troposphere with a greater precipitable water content. These limitations in the method applied here may be less problematic if the ice melt is strongly dominated by ocean melt, as has been proposed before (e.g. Pritchard and others, 2012).

Mass budgets are included in the Appendix and indicate that mass loss is dominated by basal melting of floating ice. This highlights the importance of correctly simulating sub-ice-shelf melt given that the Ross Ice Shelf undergoes collapse during phase 2 of our simulations.

The extended ABUMIP results produce a greater loss in ice mass than the extended ISMIP6 simulations. This acts as a longer demonstration of the importance of the buttressing of ice shelves on AIS mass loss already seen in ABUMIP (Sun and others, 2020). The negative feedback from bedrock rebound is revealed by these experiments, with a reduction of $\sim 1.5 \mathrm{~m} \mathrm{SLE}$ by year 3000 attributable to it. This feedback has been well documented in prior research (Gomez and others, 2010; Konrad and others, 2013; de Boer and others, 2014; Gomez and others, 2015; Larour and others, 2019) and is proposed to work in a couple of ways. As ice melts, the removal of ice mass causes the bedrock to rebound upwards creating a reduction in slope from nearby still ice-covered regions towards the newly ice-free, or ice-reduced regions. A reduced slope should tend to reduce ice sliding towards the ice-reduced regions. In addition, a grounding line with a raised bedrock due to ice-mass loss will lower or eliminate sea-water volume there, potentially reducing the basal lubrication, which could act to reduce ice outflow. In addition to these effects, glacial isostatic adjustment has a negative feedback on ice loss due to selfgravitation effects from the lowering of relative sea level as the icesheet loses mass. This is not accounted for in these simulations and should act to strengthen the negative feedback on ice loss. 


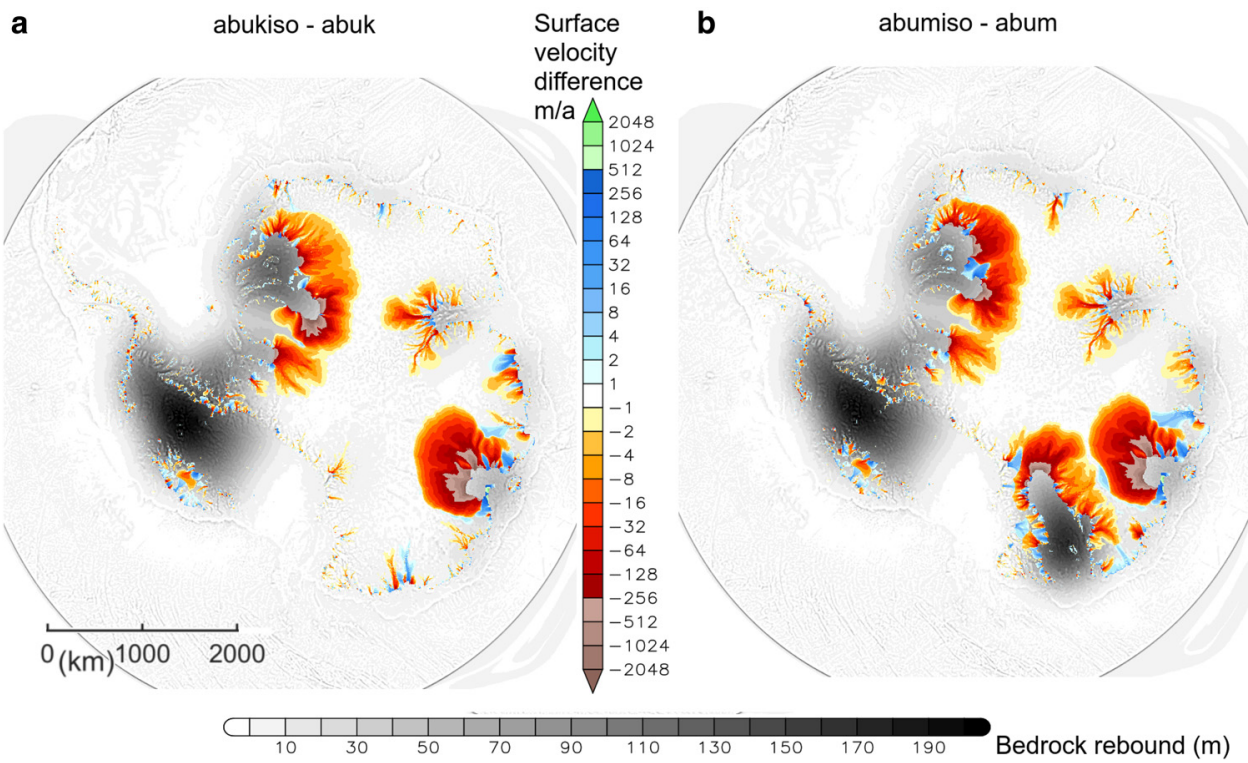

Fig. 10. Surface velocity differences between the ABUMIP bedrock rebound cases and the no rebound cases for the final simulation year (1000 years from 1990). Velocity differences are only plotted where ice exists in both the simulations. Underlain in grey shades is the bedrock rebound for (a) abukiso and (b) abumiso.
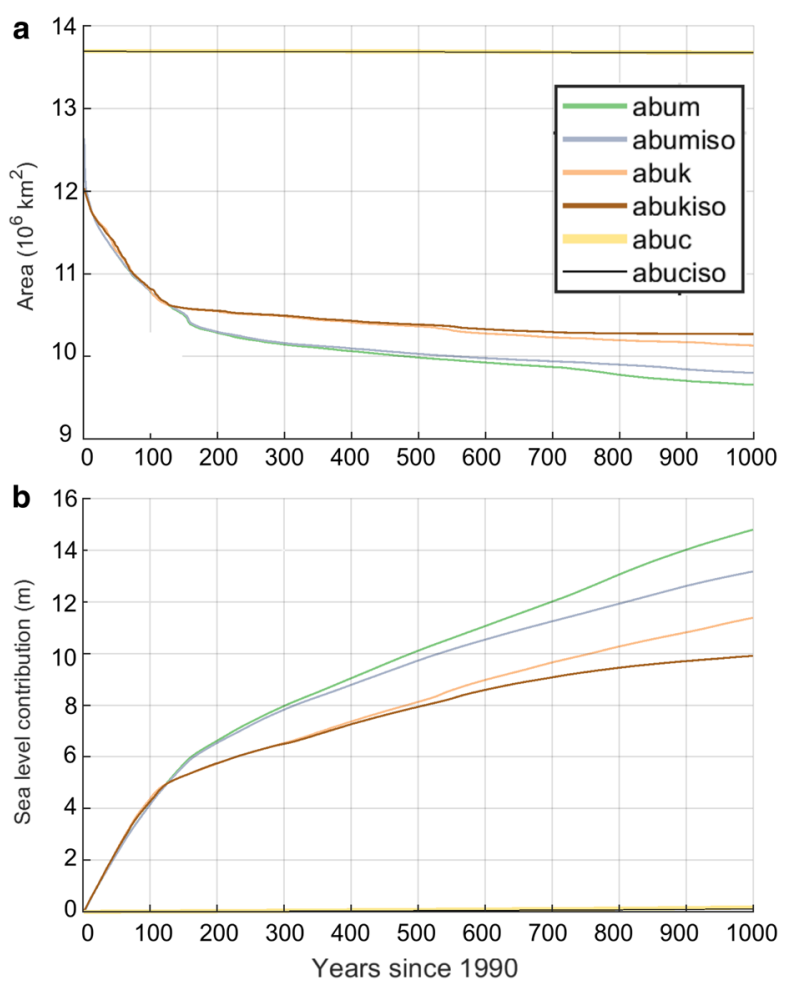

Fig. 11. ABUMIP: (a) total (grounded + floating) ice area and (b) SLE contribution.

The fact that we obtain a substantial retreat in the Wilkes Basin for the extreme ice-shelf melt experiments abum and abumiso, which does not occur in the float-kill experiments abuk and abukiso, is counter-intuitive because float-kill should be the more extreme forcing (equivalent to infinite ice-shelf melt). The same behaviour was observed for some other models of the original ABUMIP exercise (Sun and others, 2020). For SICOPOLIS, the reason is that the regional tuning of the basal sliding coefficient produces a very low value for the Wilkes Basin (Greve and others, 2020, their Fig. 4). Our version of the hybrid shallow-ice-shelfystream dynamics assumes that, below a slip ratio of $50 \%$, pure shallow-ice dynamics prevails. This is the case for almost the entire grounded region of Wilkes Basin. Therefore, in abuk and abukiso, the ice sheet does not experience a proper dynamic boundary condition at the marine front (which exists only for shelfy-stream or shallow-shelf dynamics). Rather, at the front, the grounded ice sees only the neighbouring gridpoints with zero thickness and zero velocity, which leads to an unphysical blocking of the coastward ice flow. By contrast, in abum and abumiso, mini-ice shelves can survive despite the large (but not infinite) melt rates. Therefore, the ice sheet experiences a proper boundary condition at the calving front, which allows a realistic drainage of the ice, so that it thins and retreats more compared to abuk and abukiso.

Changes to surface velocities due to bedrock rebound are dependent on the bed topography shape and the distribution of the rebound. Predominantly, this effect acts to reduce surface velocities as described above. However, there are regions where bedrock rebound increases the slope towards the ocean and can therefore act to increase ice sliding. For example on the northern coasts of the WAIS where ice remains, regions of increased velocity can be seen in Figure 10. Therefore, bedrock rebound causes a complicated redistribution of ice producing regions of increased and decreased ice flow but dominated by the larger areas where velocity decreases. These areas develop over the long term in the embayments large enough to develop the relationship with rebound described above. Studies have found that the upper mantle under the WAIS might be softer than elsewhere in Antarctica (van der Wal and others, 2015; Hay and others, 2017) and so might experience greater bedrock rebound. Therefore, there is potential for these impacts on the ice budget to be greater and more regionally dependent.

\section{Conclusion}

Ice-sheet simulations of extended versions of ISMIP6 future climate experiments for the AIS until the year 3000 have been analysed. The simulations use climate projections from the beginning of 2015 until the end of 2100, after which no further climate trend is applied, with forcing selected randomly from the final decade of the 21 st century. For the unabated 21st-century warming simulations, a large difference in the vulnerability of East and West Antarctica develops over hundreds of years, with West Antarctica suffering a much more severe ice loss than East 
Antarctica. In these cases, the mass loss amounts to an average across the simulations of $\sim 3.5 \mathrm{~m}$ SLE from 2015 to 3000 . For the optimistic pathway, the mean mass loss is $\sim 0.24 \mathrm{~m} \mathrm{SLE}$. The results are radically different to the unclear response projected over the ISMIP6 period, demonstrating that the consequences of the high-emissions scenario are much greater in the long term if a sustained, late-21st-century climate is assumed.

Under the unabated 21st-century warming scenario the ice sheet progresses through four phases, that are defined by differing rates of ice loss. In our simulations these stages are attributable to how the WAIS loses mass in the Ross Sea Embayment followed later by additional loss from the Amundsen Sea Embayment and an eventual levelling-out in the rate of ice-sheet loss once the majority of the WAIS has melted.

The ABUMIP experiments provide a demonstration of a bedrock rebound negative feedback that reduces ice loss in a similar manner as found in previous research. However, bedrock rebound can lead to faster ice flow in certain smaller areas where it acts to increase the slope towards the ocean. Limitations to our study, pointing to possible directions for future research, include the lack of accounting for local climatic changes in regions where icesheet collapse occurs causing a sharp drop in surface elevations with probable positive feedback from regional large surface temperature increases, and negative feedback from large frozen precipitation increases.

Supplementary material. The supplementary material for this article can be found at https://doi.org/10.1017/jog.2021.124

Code and data availability. SICOPOLIS is free and open-source software, available through a persistent Git repository hosted by the Alfred Wegener Institute for Polar and Marine Research (AWI) in Bremerhaven, Germany (Greve and SICOPOLIS Developer Team, 2021). Detailed instructions for obtaining and compiling the code are at available http://www.sicopolis.net (last access: 29 October 2021). The output data produced for this study are available at Zenodo, https://doi.org/10.5281/zenodo.5637796.

Acknowledgements. We thank the two anonymous reviewers and the Scientific Editor Frank Pattyn for constructive remarks and suggestions that helped to improve the manuscript. We thank the Climate and Cryosphere (CliC) effort, which provided support for ISMIP6 through sponsoring of workshops, hosting the ISMIP6 website and wiki, and promoting ISMIP6. We acknowledge the World Climate Research Programme, which, through its Working Group on Coupled Modelling, coordinated and promoted CMIP5 and CMIP6. We thank the climate modelling groups for producing their model output and making it available; the Earth System Grid Federation (ESGF) for archiving the CMIP data and providing access to it; the University at Buffalo for ISMIP6 data distribution and upload; and the multiple funding agencies who support CMIP5, CMIP6, and ESGF. We thank the ISMIP6 steering committee, the ISMIP6 model selection group and ISMIP6 dataset preparation group for their continuous engagement in defining ISMIP6. This is ISMIP6 contribution No. 25. Christopher Chambers, Ralf Greve and Ayako Abe-Ouchi were supported by Japan Society for the Promotion of Science (JSPS) KAKENHI Grant No. JP17H06323. Ralf Greve and Ayako Abe-Ouchi were supported by JSPS KAKENHI Grant No. JP17H06104. Takashi Obase, Fuyuki Saito and Ayako Abe-Ouchi were supported by JSPS Grant-in-Aid for Japan-France Integrated Action Program (SAKURA Program) No. JPJSBP120213203.

\section{References}

Alley RB and 7 others (2015) Oceanic forcing of ice-sheet retreat: West Antarctica and more. Annual Review of Earth and Planetary Sciences 43 (1), 207-231. doi: 10.1146/annurev-earth-060614-105344

Bamber JL, Riva REM, Vermeersen BLA and LeBrocq AM (2009) Reassessment of the potential sea-level rise from a collapse of the West Antarctic ice sheet. Science (New York, N.Y.) 324(5929), 901-903. doi: 10. 1126/science.1169335

Barthel A and 9 others (2020) CMIP5 model selection for ISMIP6 ice sheet model forcing: Greenland and Antarctica. The Cryosphere 14(3), 855-879. doi: $10.5194 / \mathrm{tc}-14-855-2020$
Bernales J, Rogozhina I, Greve R and Thomas M (2017) Comparison of hybrid schemes for the combination of shallow approximations in numerical simulations of the Antarctic ice sheet. The Cryosphere 11(1), 247-265. doi: 10.5194/tc-11-247-2017

Bulthuis K, Arnst M, Sun S and Pattyn F (2019) Uncertainty quantification of the multi-centennial response of the Antarctic ice sheet to climate change. The Cryosphere 13(4), 1349-1380. doi: 10.5194/tc-13-1349-2019

Calov R and 8 others (2018) Simulation of the future sea level contribution of Greenland with a new glacial system model. The Cryosphere 12(10), 30973121. doi: 10.5194/tc-12-3097-2018

de Boer B, Stocchi P and van de Wal RSW (2014) A fully coupled 3-D icesheet-sea-level model: algorithm and applications. Geoscientific Model Development 7(5), 2141-2156. doi: 10.5194/gmd-7-2141-2014

Dutton A and 7 others (2015) Sea-level rise due to polar ice-sheet mass loss during past warm periods. Science (New York, N.Y.) 349(6244), aaa4019. doi: $10.1126 /$ science.aaa4019

Edwards TL and 83 others (2021) Projected land ice contributions to twenty-first-century sea level rise. Nature 593(7857), 74-82. doi: 10.1038/ s41586-021-03302-y

Eyring V and 6 others (2016) Overview of the Coupled Model Intercomparison Project Phase 6 (CMIP6) experimental design and organization. Geoscientific Model Development 9(5), 1937-1958. doi: 10.5194/ gmd-9-1937-2016

Fretwell P and 59 others (2013) Bedmap2: improved ice bed, surface and thickness datasets for Antarctica. The Cryosphere 7(1), 375-393. doi: 10. 5194/tc-7-375-2013

Frieler K and 8 others (2015) Consistent evidence of increasing Antarctic accumulation with warming. Nature Climate Change 5(4), 348-352. doi: 10.1038/nclimate 2574

Garbe J, Albrecht T, Levermann A, Donges JF and Winkelmann R (2020) The hysteresis of the Antarctic ice sheet. Nature 585(7826), 538-544. doi: 10.1038/s41586-020-2727-5

Gasson E, DeConto RM, Pollard D and Levy RH (2016) Dynamic Antarctic ice sheet during the early to mid-Miocene. Proceedings of the National Academy of Sciences 113(13), 3459-3464. doi: 10.1073/pnas.1516130113

Gladstone RM, and 5 others (2017) Marine ice sheet model performance depends on basal sliding physics and sub-shelf melting. The Cryosphere 11(1), 319-329. doi: 10.5194/tc-11-319-2017

Golledge NR, and 5 others (2015) The multi-millennial Antarctic commitment to future sea-level rise. Nature 526(7573), 421-425. doi: 10.1038/nature15706

Gomez N, Mitrovica JX, Huybers P and Clark PU (2010) Sea level as a stabilizing factor for marine-ice-sheet grounding lines. Nature Geoscience 3 (12), 850-853. doi: 10.1038/ngeo1012

Gomez N, Pollard D and Holland D (2015) Sea-level feedback lowers projections of future Antarctic ice-sheet mass loss. Nature Communications 6(1), 8798. doi: $10.1038 /$ ncomms 9798

Greve R (1995) Thermomechanisches Verhalten polythermer Eisschilde - Theorie, Analytik, Numerik. Doctoral thesis, Department of Mechanics, Darmstadt University of Technology, Germany. doi: 10.5281/zenodo.3775042.

Greve R (1997) Application of a polythermal three-dimensional ice sheet model to the Greenland ice sheet: response to steady-state and transient climate scenarios. Journal of Climate 10(5), 901-918. doi: 10.1175/1520-0442 (1997)010<0901:AOAPTD >2.0.CO;2

Greve R and 5 others (2020) ISMIP6 future projections for the Antarctic ice sheet with the model SICOPOLIS. Technical report, Zenodo. doi: 10.5281/ zenodo.3971232.

Greve R, SICOPOLIS Developer Team (2021) SICOPOLIS. GitLab, Alfred Wegener Institute for Polar and Marine Research, Bremerhaven, Germany, URL https://gitlab.awi.de/sicopolis/sicopolis.

Hay CC and 7 others (2017) Sea level fingerprints in a region of complex earth structure: the case of Wais. Journal of Climate 30(6), 1881-1892. doi: 10.1175/JCLI-D-16-0388.1

The IMBIE team (2018) Mass balance of the Antarctic ice sheet from 1992 to 2017. Nature 558(7709), 219-222. doi: 10.1038/s41586-018-0179-y

Joughin I and Alley RB (2011) Stability of the West Antarctic ice sheet in a warming world. Nature Geoscience 4(8), 506-513. doi: 10.1038/ngeo1194

Joughin I, Smith BE and Medley B (2014) Marine ice sheet collapse potentially under way for the Thwaites Glacier Basin, West Antarctica. Science (New York, N.Y.) 344(6185), 735-738. doi: 10.1126/science.1249055

Jourdain NC and 6 others (2020) A protocol for calculating basal melt rates in the ISMIP6 Antarctic ice sheet projections. The Cryosphere 14(9), 31113134. doi: $10.5194 / \mathrm{tc}-14-3111-2020$ 
Konrad H and 6 others (2013) The deformational response of a viscoelastic solid earth model coupled to a thermomechanical ice sheet model Surveys in Geophysics. 35(6), 1441-1458. doi: 10.1007/s10712-013-9257-8.

Krinner G, Magand O, Simmonds I, Genthon C and Dufresne JL (2007) Simulated Antarctic precipitation and surface mass balance at the end of the twentieth and twenty-first centuries. Climate Dynamics 28(2-3), 215230. doi: 10.1007/s00382-006-0177-x

Larour E and 6 others (2019) Slowdown in Antarctic mass loss from solid earth and sea-level feedbacks. Science (New York, N.Y.) 364(6444), eaav7908. doi: 10.1126/science.aav7908

Levermann A and 6 others (2013) The multimillennial sea-level commitment of global warming. Proceedings of the National Academy of Sciences 110(34), 13745-13750. doi: 10.1073/pnas.1219414110

Levermann A and Winkelmann R (2016) A simple equation for the melt elevation feedback of ice sheets. The Cryosphere 10(4), 1799-1807. doi: 10 5194/tc-10-1799-2016

Ligtenberg SRM, van de Berg WJ, van den Broeke MR, Rae JGL and van Meijgaard E (2013) Future surface mass balance of the Antarctic ice sheet and its influence on sea level change, simulated by a regional atmospheric climate model. Climate Dynamics 41(3-4), 867-884. doi: 10.1007/ s00382-013-1749-1

Lipscomb WH and 5 others (2021) ISMIP6-based projections of ocean-forced Antarctic ice sheet evolution using the Community Ice Sheet Model. The Cryosphere 15(2), 633-661. doi: 10.5194/tc-15-633-2021

Mercer JH (1968) Antarctic ice and Sangamon sea level. In Bern General Assembly, Commission of Snow and Ice, 1967, Vol. 79, International Association of Hydrological Sciences, IAHS Publication, pp. 217-225.

Nowicki SMJ and 8 others (2016) Ice Sheet Model Intercomparison Project (ISMIP6) contribution to CMIP6. Geoscientific Model Development 9(12) 4521-4545. doi: 10.5194/gmd-9-4521-2016

Nowicki S and 29 others (2020) Experimental protocol for sea level projections from ISMIP6 stand-alone ice sheet models. The Cryosphere 14(7), 2331-2368. doi: 10.5194/tc-14-2331-2020

Payne AJ and 63 others (2021) Future sea level change under CMIP5 and CMIP6 scenarios from the Greenland and Antarctic ice sheets. Geophysical Research Letters 48(6), e2020GL091741.doi: 10.1029/ 2020GL091741

Pollard D and DeConto RM (2009) Modelling West Antarctic ice sheet growth and collapse through the past five million years. Nature 458 (7236), 329-332. doi: 10.1038/nature07809

Pritchard HD and 5 others (2012) Antarctic ice-sheet loss driven by basal melting of ice shelves. Nature 484(7395), 502-505. doi: 10.1038/ nature 10968
Rignot E and Mouginot J (2016) Antarctica and Greenland drainage basin and ice sheet definitions. IMBIE 2016.

Rignot E, Mouginot J, Morlighem M, Seroussi H and Scheuchl B (2014) Widespread, rapid grounding line retreat of Pine Island, Thwaites, Smith and Kohler glaciers, West Antarctica, from 1992 to 2011. Geophysical Research Letters 41(10), 3502-3509. doi: 10.1002/2014GL060140

Sato T and Greve R (2012) Sensitivity experiments for the Antarctic ice sheet with varied sub-ice-shelf melting rates. Annals of Glaciology 53(60), 221228. doi: 10.3189/2012AoG60A042

Schaeffer M, Hare W, Rahmstorf S and Vermeer M (2012) Long-term sealevel rise implied by $1.5^{\circ} \mathrm{C}$ and $2^{\circ} \mathrm{C}$ warming levels. Nature Climate Change 2(12), 867-870. doi: 10.1038/nclimate1584

Schoof C (2007) Ice sheet grounding line dynamics: steady states, stability, and hysteresis. Journal of Geophysical Research: Earth Surface 112(F3), F03S28. doi: 10.1029/2006JF000664

Seroussi H and 46 others (2020) ISMIP6 Antarctica: a multi-model ensemble of the Antarctic ice sheet evolution over the 21st century. The Cryosphere 14 (9), 3033-3070. doi: 10.5194/tc-14-3033-2020

Sun $S$ and 28 others (2020) Antarctic ice sheet response to sudden and sustained ice-shelf collapse (ABUMIP). Journal of Glaciology 66(260), 891904. doi: $10.1017 /$ jog.2020.67

Trusel LD and 6 others(2015) Divergent trajectories of Antarctic surface melt under two twenty-first-century climate scenarios. Nature Geoscience 8(12), 927-932. doi: 10.1038/ngeo2563

Turney CSM and 31 others (2020) Early Last Interglacial ocean warming drove substantial ice mass loss from Antarctica. Proceedings of the National Academy of Sciences 117(8), 3996-4006. doi: 10.1073/pnas. 1902469117

Uotila P, Lynch AH, Cassano JJ and Cullather RI (2007) Changes in Antarctic net precipitation in the 21st century based on Intergovernmental Panel on Climate Change (IPCC) model scenarios. Journal of Geophysical Research: Atmospheres 112(D10), D10107. doi: 10. 1029/2006JD007482

van der Wal W, Whitehouse PL and Schrama EJ (2015) Effect of GIA models with 3D composite mantle viscosity on GRACE mass balance estimates for Antarctica. Earth and Planetary Science Letters 414, 134-143. doi: 10.1016/j. epsl.2015.01.001

\section{Appendix}

This appendix presents additional cross sections and mass budgets for the MIROC-ESM-CHEM RCP8.5 case. Considered first are four EAIS cross a

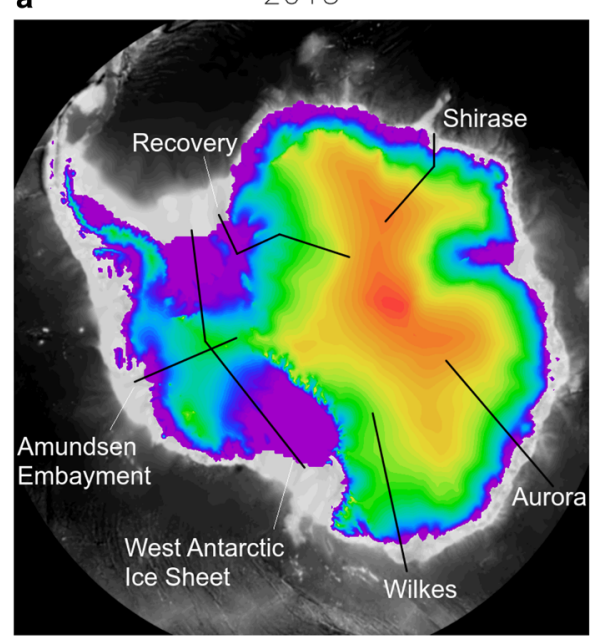

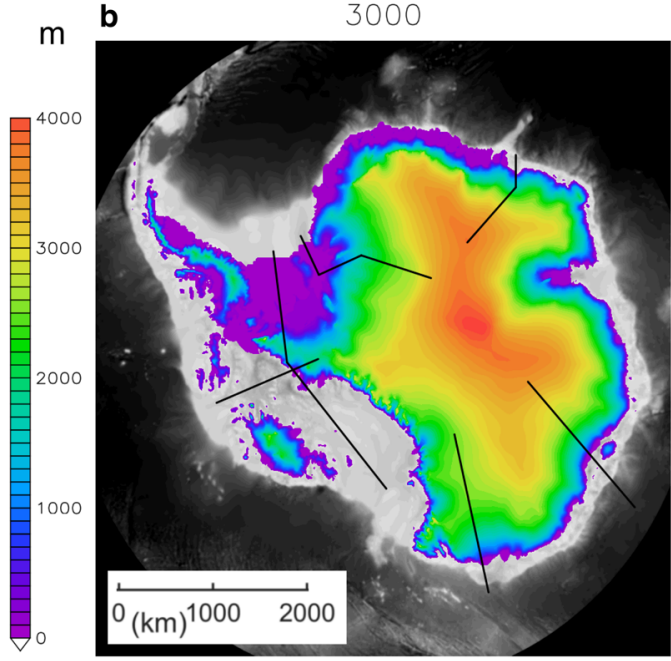

Fig. 12. Cross section locations on surface topography for the MIROC-ESM-CHEM RCP8.5 experiment for a) 2015, and b) 3000 . Included are cross section locations for the WAIS used in Figure 4 and the Amundsen Embayment in Figure 6. 

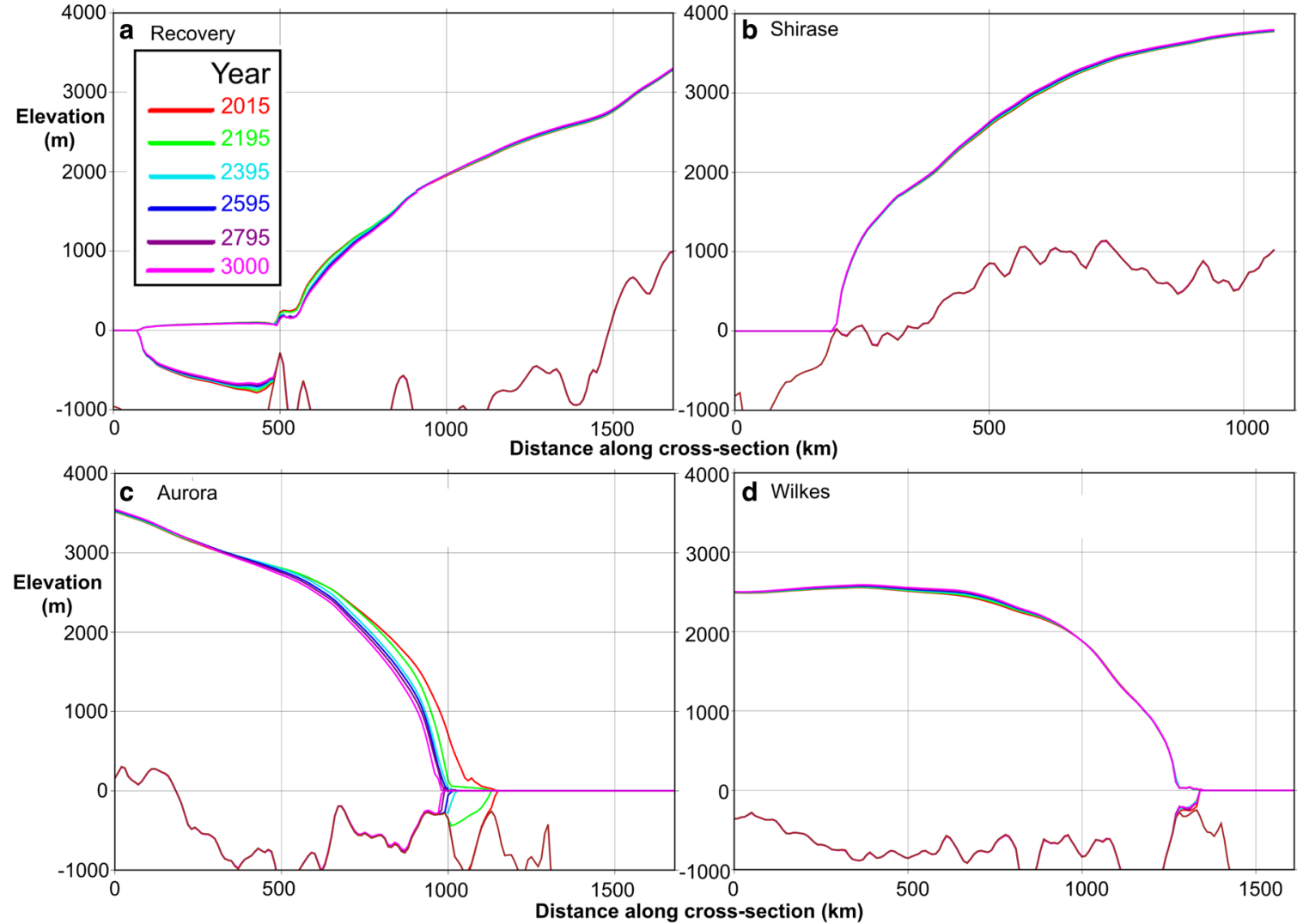

Fig. 13. EAIS ice profile cross sections for a) Recovery, b) Shirase, c) Aurora, and d) Wilkes for the years indicated.

\section{a Antarctica}

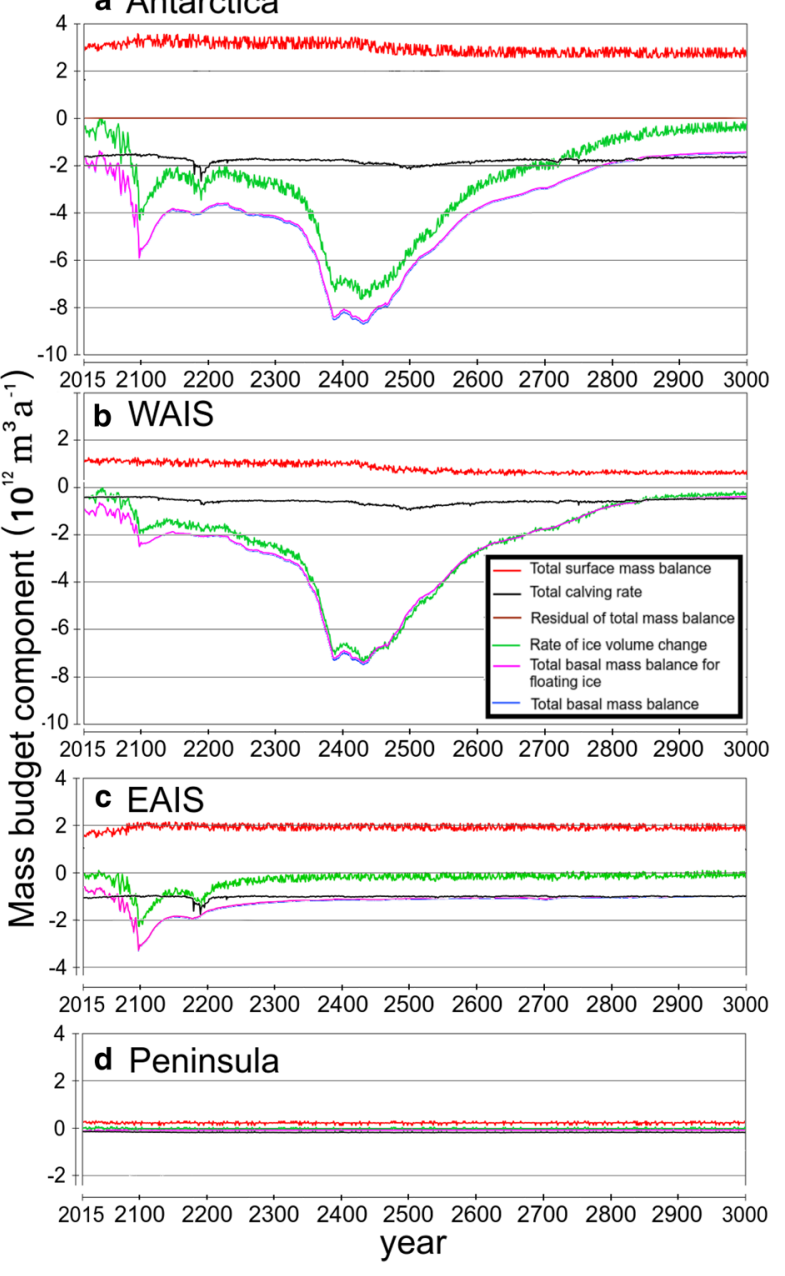

sections, guided by the ice flowline, for the Recovery, Shirase, Aurora and Wilkes basins. The locations of the cross sections, as well as those shown earlier in Figures 4 and 6, are in Figure 12. The cross sections shown in Figure 13 all show far less change than those for the WAIS. In the extreme, the Shirase section shows so little ice change at the coast that all profiles from 2015 to 3000 appear to overlap to form one line. The only change in this profile is from the slow thickening of the interior ice. The Recovery and Wilkes cross sections show some minor ice shelf basal melt, however there again is essentially no coastal retreat. Of the four, the Aurora basin has the greatest response with $\sim 150 \mathrm{~km}$ retreat in the ice at the coast. The loss in coastal ice, combined with the thickening of interior ice, steepens the ice-sheet slopes slightly, with the greatest steepening in the Aurora basin. Further investigation is recommended to determine why so little simulated change is seen in East Antarctica.

Secondly, mass budgets are shown in Figure 14. The mass loss is driven almost entirely by basal mass loss from floating ice. Comparing the regionally divided figures indicates that the rapid ice loss during phase 3 is driven primarily by basal mass loss from floating ice in the WAIS. The sharp dip in the rate of volume change around 2100 is associated with the transition from a warming climate to a constant climate. The total surface mass balance declines between 2100 and 3000 over the WAIS. This may be due to the reduction in surface ice area or the redistribution of ice away from areas of positive mass balance in the end of 21 st-century forcing data used.

Fig. 14. Mass budget components for the MIROC-ESM-CHEM RCP8.5 case for a) all 